\title{
Acceptance of birth spacing methods and it's determinants among postnatal women in a tertiary care setting from Kerala
}

\author{
Revathy P. Nair, Bindu Nambisan*, Mayadevi Brahmanandan
}

Department of Obstetrics and Gynaecology, Medical College, Trivandrum, Kerala, India

Received: 08 August 2021

Accepted: 04 September 2021

\author{
*Correspondence: \\ Dr. Bindu Nambisan, \\ E-mail: bindu.nambisan1971@gmail.com
}

Copyright: ( ) the author(s), publisher and licensee Medip Academy. This is an open-access article distributed under the terms of the Creative Commons Attribution Non-Commercial License, which permits unrestricted non-commercial use, distribution, and reproduction in any medium, provided the original work is properly cited.

\begin{abstract}
Background: According to VISION FP2020 healthy birth spacing is defined as delaying the first birth by two years and maintaining the birth interval of at least three years between the two children with the help of various contraceptives.

Methods: This was a hospital based cross sectional study conducted among primiparous postnatal women in the department of obstetrics and gynecology SAT hospital, Trivandrum for one year duration. 134 women who had their first delivery were included in this study. A semi structured questionnaire was used to study the sociodemographic variables, reproductive history, contraceptive knowledge, attitude towards contraception and intention to use birth spacing methods by interview technique.

Results: The acceptance of birth spacing methods among the study population was $56.8 \% .59 .1 \%$ opted to use family planning methods 6 weeks after delivery while $40.9 \%$ planned to use after 6 months. Determinants which were significantly associated with acceptance of family planning methods were education of wife $(\mathrm{p}<0.01)$, husbands' education, socioeconomic status, religion and contraceptive awareness ( $\mathrm{p}<0.01$ ). $47.1 \%$ of women preferred DMPA injections, $39.1 \%$ opted for intrauterine devices. $13.8 \%$ of women opted for condom. Convenience, long term protection, and ease of use were the important reasons cited. The reasons for non-acceptance included fear of side effects, spouse not staying together, opposition from husbands, lack of awareness and religious restrictions.

Conclusions: Female literacy, accessibility, cafeteria approach, and counselling contributed to acceptance. If the availability and awareness of injectable contraceptives is made at all the points of health delivery system, the acceptance of birth spacing can further be increased and unplanned pregnancies avoided.
\end{abstract}

Keywords: Contraception, Birth spacing, Health education, Intrauterine devices, Cross sectional study

\section{INTRODUCTION}

Healthy birth spacing is defined as delaying the first birth by two years and maintaining the birth interval of at least three years between the two children through the use of contraceptive methods. Family planning is widely acknowledged as an important intervention towards achieving Millennium Development Goals four and five as it has proven to reduce maternal and child mortality. ${ }^{1-3}$ It can prevent unwanted pregnancies, unsafe abortions, and also STD's. According to National family health survey-4, the median interval between births in India is 31 months. ${ }^{4}$ The acceptance of birth spacing methods is only $8 \%$ in which IUD/PPIUD accounts for $1.6 \%$, contraceptive pills; $0.2 \%$ and condoms; $2.6 \%$. Between the ages of 20 and 44, a fertile, sexually-active woman is potentially capable of giving birth about 12 times, even if she breastfeeds each baby for 1 year. To avoid the need for an abortion, she has to successfully practice birth control for $16-20$ of her roughly 25 childbearing years. ${ }^{5}$ The acceptance of contraceptive methods varies within societies and also among different castes and religious 
groups. Many of the nursing mothers who prefer to delay next pregnancy are unaware of family planning practices. The traditional methods of birth spacing were coitus interrupts or withdrawal, lactational amenorrhea method and rhythm method.

Modern methods include barrier methods, oral contraceptive pills, injectables the most common of which is depot medroxy progesterone acetate (DMPA). Intrauterine device is another popular and cost effective method in use in India. These methods are started soon after menstruation, abortion, or 6 weeks postpartum. Unwanted pregnancies end up with abortions, the social stigma surrounding which lead on to unsafe practices. Unsafe abortions can lead to increased maternal morbidity and mortality. World over, if contraception is accessible and used consistently and correctly by women wanting to avoid pregnancy, maternal deaths would decline by an estimated $25-35 \% .{ }^{6,7}$ A leading national English newspaper reported a staggering $90 \%$ or 9.2 lakh women in India were estimated to require abortion services but could not access them between January and June 2020 because of stringent COVID lockdown. It was also reported that this could lead to as many as 10 lakh unsafe abortions, 6.5 lakh unintended pregnancies, and 2600 maternal deaths, which is unacceptable. Here lies the importance of planned and timed pregnancies and the need for effective birth spacing methods.

Family planning measures play an important role in maternal health. It also impacts child survival and perinatal outcomes positively. Children born within 2 years of an elder sibling have a $60 \%$ increased risk of infant death, compared with those born after 3 years or longer. Compared with inter-pregnancy intervals of 1.5 to 2 years, inter-pregnancy intervals shorter than 6 months cause an increase of $40 \%$ risks of preterm births and $60 \%$ risk of low birth weight. ${ }^{8}$ Contraception for all women in developing countries could prevent up to 54 million unintended pregnancies, 26 million abortions (out of which 16 million would be unsafe) 7 million miscarriages, 79,000 maternal deaths as well as 1.1 million infant deaths ${ }^{9}$. Expanding access to contraception is therefore critical to achieving the post-2015 development agenda across the 5 SDGs themes of people, planet, prosperity, peace and partnerships.

Unmet need of family planning has been consistently used to monitor and evaluate sexual and reproductive health programs in the framework of the MDGs. ${ }^{10,11}$ In India, the unmet need for family planning are as follows: Total unmet need was $13.7 \%$ and unmet need for spacing was $8.3 \%$. India's FP2020 commitment is to provide 48 million additional women with modern contraceptives. ${ }^{11}$ Ensuring Spacing at Birth (ESB) was a new scheme launched by the Government of India, where services of ASHAs were utilized for counselling newly married couples to ensure spacing of 2 years after marriage and couples with 1 child to have spacing of 3 years after the birth of 1 st child. The scheme is operational in 18 states.

\section{Aim and objectives}

Aim and objectives of current study were; to study the acceptance of birth spacing methods of contraceptive use among women attending postnatal clinic and to identify the determinants for acceptance of these methods and the commonest method preferred.

\section{METHODS}

\section{Study design, setting and duration}

Current study is a hospital based cross-sectional study conducted at postnatal clinic in department of obstetrics and gynecology of SAT hospital, Trivandrum from February 2018 to January 2019.

\section{Study population}

Primiparous women attending postnatal clinic of SATH, Trivandrum for postnatal check up were taken as study participants.

\section{Inclusion criteria}

Women with one living child attending postnatal clinic of SAT hospital for postnatal checkup at 6 weeks postpartum were included in the study.

\section{Exclusion criteria}

Women who did not give consent, who had a bad obstetric history, women with psychiatric disorder, widows, divorced and separated females were excluded from the study.

\section{Sample size}

Sample size was calculated based on a pilot study conducted in same setting on 50 postnatal women, where the acceptance of birth spacing methods came as $58 \%$. Sample size calculated by the formula;

$$
\mathrm{n}=4 \mathrm{pq} / \mathrm{d}^{2}
$$

Where $\mathrm{P}=$ acceptance of birth spacing method $=58 \%$ (from the pilot study) $\mathrm{q}=100-\mathrm{P}=42, \mathrm{~d}=20 \%$ of $\mathrm{P}=11.6 \mathrm{n}=72$ The sample size as per pilot study was 72, but total 134 samples were collected for better outcome on determinants for acceptance of family planning methods.

\section{Study variables}

Socio demographic factors like age, educational status and occupation of husband and wife, their monthly income, socioeconomic status and religion were examined. Reproductive history, contraceptive knowledge, attitude towards contraception and intention to use birth spacing methods were also studied. 


\section{Data collection tool}

A semi structured questionnaire which included necessary questions regarding study variables was prepared. Women attending the postnatal clinic for postnatal checkup satisfying the inclusion and exclusion criteria were selected. They were interviewed with the semi structured questionnaire on an individual basis. A brief counseling and education regarding the various contraceptive practices was given to postnatal patients including the advantages and disadvantages of each method. Informed consent was obtained from the participants. Confidentiality was ensured and maintained throughout the study

\section{Statistical analysis}

The obtained data was entered in excel sheet and analyzed by appropriate test using SPSS software. Quantitative variables are expressed as mean and standard deviation. Qualitative variables are expressed using percentage. Association of different variables were assessed using Chi square test

\section{RESULTS}

\section{Demographic characteristics}

In this study majority of women were of age group of 21$25 y$ rs $(36.5 \%)$ with a mean age of 23.1 . Total $47.5 \%$ of study population had secondary education and $47 \%$ had higher education. A small percentage $(5.5 \%)$ had primary education only. $60.5 \%$ of study population had husbands with higher education and $38.5 \%$ had secondary education. $57 \%$ of study population belonged to above poverty line and $43 \%$ of population were below poverty line. $98 \%$ of the study population belonged to nuclear family, $2 \%$ belonged to joint family. In this study, $68 \%$ of the subjects were Hindus, $13 \%$ Muslims and $19 \%$ were Christians (Table 1).

\section{Obstetric factors and contraception acceptance}

$100 \%$ in this study were married once. Majority of subjects were married for 1-3 years. Accounting for $88.05 \%, 7.40 \%$ of the study population had more than $3 y r s$ of marriage duration and $4.5 \%$ were married for less than one year. $20 \%$ of the study population had previous one abortion, $10 \%$ had 2 abortions and $70 \%$ of the subjects did not had a history of previous abortion (Table 2).

\section{Mode of delivery}

$62.5 \%$ of the study subjects had vaginal delivery, $36.5 \%$ had caesarean sections and $1 \%$ had instrumental deliveries

\section{Sex of baby}

$57.5 \%$ had female child while $42.5 \%$ of subjects had male child in their present pregnancy.

\section{Birth weight}

Total $86 \%$ of the study population had normal birth weight babies of $2.5-4 \mathrm{~kg}, 14 \%$ had low birth weight babies of less than $2.5 \mathrm{~kg}$

\section{Decision making on family size}

In $98.5 \%$ cases the couple decisions were based on mutual consensus, whereas in $1.5 \%$ cases it was the husband who decided the family size

\section{Decision regarding the next planned pregnancy}

91.5\% planned to have their next child after 3 years and $8.5 \%$ planned to have their next child after 2 yrs. The reasons for not having the next child within one year were: planning to use family planning methods in $59.5 \%$, $23 \%$ plan to avoid sex for next one-year and $17.5 \%$ had their partners staying abroad.

\section{Contraceptive awareness}

Of the total study population $95 \%$ of the subjects had contraceptive awareness and 5\% had not heard of contraception. The source of information about contraception was mainly health education accounting for $94 \%$, followed by mass media $61.5 \%$. Knowledge from family members $(26 \%)$ and friends $(8 \%)$ also act as a source of information in a few study subjects (Figure 1).

\section{Knowledge of family planning method}

Majority had knowledge about oral pills (91\%) and condoms $(92.5 \%)$, followed by permanent sterilization (89\%). $21.5 \%$ had knowledge about emergency pills, $47 \%$ knew about intrauterine devices, $44.5 \%$ knew about injectables. Rhythm method and withdrawal method as a method of contraception was known to very few, $9.5 \%$ and $2.5 \%$ respectively. $0.5 \%$ had knowledge of implants. (Figure 2). Perception of impact of contraception on family life: $76.5 \%$ of the subjects thought that contraception helped couples to become responsible parents, $23 \%$ of the subjects had no idea on whether contraception helped to become responsible parents.

\section{Knowledge regarding availability of family planning methods}

Total $94 \%$ of women knew about availability in public hospitals, $4.5 \%$ knew about availability in private hospitals and $46 \%$ knew about availability in pharmacies. 
Table 1: Comparison of demographic variables based on acceptance of birth spacing methods among postnatal women.

\begin{tabular}{|c|c|c|c|c|c|c|c|}
\hline & & Use far & Jannir & ods & & & \\
\hline Parameters & & Yes & & No & & $\mathrm{X}^{2}$ & $P$ value \\
\hline & & Count & $\%$ & Count & $\%$ & & \\
\hline & $19-22$ & 25 & 62.5 & 15 & 37.5 & & \\
\hline$A \sim 0$ & $23-25$ & 27 & 56.3 & 21 & 43.8 & 0.03 & 0818 \\
\hline Age & $26-30$ & 27 & 55.1 & 22 & 44.9 & 0.93 & 0.818 \\
\hline & $>30$ & 9 & 50.0 & 9 & 50.0 & & \\
\hline & Primary/sec & 34 & 44.7 & 42 & 55.3 & & \\
\hline Wite's eduction & higher & 54 & 68.4 & 25 & 31.6 & 8.8 & 0.003 \\
\hline & Primary/sec & 25 & 44.6 & 31 & 55.4 & 506 & \\
\hline Huspand s equeation & higher & 63 & 63.6 & 36 & 36.4 & 5.20 & 0,012 \\
\hline Income & $5000-10000$ & 27 & 48.2 & 29 & 51.8 & & 0.106 \\
\hline Income & $>10000$ & 61 & 61.6 & 38 & 38.4 & 2.62 & 0.106 \\
\hline Socio-oconomic status & APL & 58 & 62.4 & 35 & 37.6 & 206 & 0.015 \\
\hline Socio-economic status & BPL & 30 & 48.4 & 32 & 51.6 & 2.90 & 0.015 \\
\hline & Hindu & 67 & 63.2 & 39 & 36.8 & & \\
\hline Religion & Muslim & 8 & 38.1 & 13 & 61.9 & 5.99 & 0.005 \\
\hline & Christian & 13 & 46.4 & 15 & 53.6 & & \\
\hline
\end{tabular}

Table 2: Comparison of obstetric factors and acceptance of birth spacing methods among postnatal women.

\begin{tabular}{|c|c|c|c|c|c|c|c|}
\hline \multirow{3}{*}{ Parameters } & & \multicolumn{4}{|c|}{ Use of family planning methods } & \multirow{3}{*}{$\mathrm{X}^{2}$} & \multirow{3}{*}{$P$ value } \\
\hline & & \multicolumn{2}{|l|}{ Yes } & \multicolumn{2}{|l|}{ No } & & \\
\hline & & Count & $\%$ & Count & $\%$ & & \\
\hline \multirow{2}{*}{$\begin{array}{l}\text { Duration of marriage } \\
\text { (years) }\end{array}$} & $<3$ & 67 & 56.8 & 51 & 43.2 & \multirow{2}{*}{0} & \multirow{2}{*}{0.998} \\
\hline & $>3$ & 21 & 56.8 & 16 & 43.2 & & \\
\hline \multirow{2}{*}{ Type of delivery } & Vaginal delivery & 44 & 50.6 & 43 & 49.4 & \multirow{2}{*}{3.11} & \multirow{2}{*}{0.078} \\
\hline & C-Section & 44 & 64.7 & 24 & 35.3 & & \\
\hline \multirow{2}{*}{ Sex of baby } & Male & 35 & 54.7 & 29 & 45.3 & \multirow{2}{*}{0.19} & \multirow{2}{*}{0.660} \\
\hline & Female & 53 & 58.2 & 38 & 41.8 & & \\
\hline \multirow{2}{*}{ Birth weight (kg) } & $<2.5$ & 14 & 60.9 & 9 & 39.1 & \multirow{2}{*}{0.18} & \multirow{2}{*}{0.667} \\
\hline & $2.5-4$ & 74 & 56.1 & 58 & 43.9 & & \\
\hline \multirow{2}{*}{ No of deliveries } & one & 74 & 56.1 & 58 & 43.9 & \multirow{2}{*}{0.18} & \multirow{2}{*}{0.667} \\
\hline & >one & 14 & 60.9 & 9 & 39.1 & & \\
\hline \multirow{2}{*}{ No of children } & one & 75 & 56.0 & 59 & 44.0 & \multirow{2}{*}{0.26} & \multirow{2}{*}{0.610} \\
\hline & >one & 13 & 61.9 & 8 & 38.1 & & \\
\hline \multirow{3}{*}{ Abortions } & one & 14 & 51.9 & 13 & 48.1 & \multirow{3}{*}{0.84} & \multirow{3}{*}{0.656} \\
\hline & Two or more & 9 & 50.0 & 9 & 50.0 & & \\
\hline & none & 65 & 59.1 & 45 & 40.9 & & \\
\hline \multirow{2}{*}{$\begin{array}{l}\text { Contraceptive } \\
\text { awareness }\end{array}$} & yes & 88 & 60.7 & 57 & 39.3 & \multirow{2}{*}{14.04} & \multirow{2}{*}{$<0.01$} \\
\hline & No & 0 & 0.0 & 10 & 100 & & \\
\hline
\end{tabular}

\section{Knowledge of the general uses of contraceptives}

The general uses of contraception that was known to the study population were; child spacing $(85.5 \%)$ of the subjects, limiting the number of children (78\%), 34\% knew that it helped to prevent unwanted pregnancy and
$5 \%$ had no knowledge on general uses of contraception (Table 3).

\section{Attitude towards contraception}

The attitude of study population towards contraception was as follows; husbands decided if wife should use 
family planning methods in $14 \%$ of the population. $84.5 \%$ of women were aware that child spacing protected mother and child.

Table 3: Percentage distribution of the sample according to knowledge of the general uses of contraceptive.

\begin{tabular}{|lll|}
\hline $\begin{array}{l}\text { Knowledge of the general uses of } \\
\text { contraceptive }\end{array}$ & Count & $\%$ \\
\hline $\begin{array}{l}\text { Helps prevention of unwanted } \\
\text { pregnancy }\end{array}$ & 46 & 34.0 \\
\hline Limiting number of children & 105 & 78.0 \\
\hline Child spacing & 115 & 85.5 \\
\hline Don't know & 6 & 4.5 \\
\hline
\end{tabular}

$24 \%$ of the subjects thought that family planning methods have side effects. $1 \%$ thought that family planning will cause a loss of confidence between couples. $57.5 \%$ of subjects thought that men should also take the responsibility of family planning use. $78.5 \%$ thought that contraception helped to regain strength after a child birth by birth spacing (Table 4 ).

Table 4: Percentage distribution of the sample according to attitude towards contraception.

\begin{tabular}{|c|c|c|}
\hline Attitude towards contraception & Count & $\%$ \\
\hline $\begin{array}{l}\text { Husband decides if wife wants to } \\
\text { use birth spacing }\end{array}$ & 19 & 14.0 \\
\hline $\begin{array}{l}\text { Child spacing protects mother and } \\
\text { child }\end{array}$ & 113 & 84.5 \\
\hline FP methods have side effects & 32 & 24 \\
\hline $\begin{array}{l}\text { Family planning will cause a loss of } \\
\text { confidence between couples }\end{array}$ & 1 & 1.0 \\
\hline $\begin{array}{l}\text { Men should share responsibility of } \\
\text { family planning use }\end{array}$ & 77 & 57.5 \\
\hline $\begin{array}{l}\text { Contraception helps to regain } \\
\text { strength }\end{array}$ & 105 & 78.5 \\
\hline
\end{tabular}

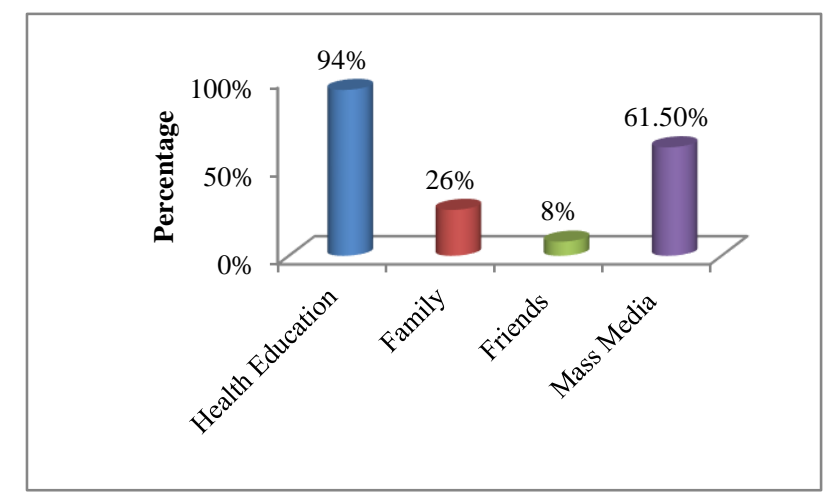

Figure 1: Source of awareness of contraception.

The acceptance of birth spacing methods among the study population was $56.8 \%$ which was a very good number compared to the statistics all over the country. $59.1 \%$ planned to use family planning methods 6 weeks after delivery while $40.9 \%$ planned to use it 6 months after delivery. Out of the various determinants studied, those which were significantly associated with acceptance of family planning methods were education of wife $(\mathrm{p}=0.003)$ husband's education $\quad(\mathrm{p}=0.012)$, ( socioeconomic status $(\mathrm{p}=0.015)$, religion $(\mathrm{p}=0.005)$ and contraceptive awareness $(\mathrm{p}<0.01)$ (Table 4$)$. The most common birth spacing method preferred was DMPA injection in about $30.8 \%$ women and intrauterine devices in about $25.6 \%$. $9 \%$ opted for condom, especially those who had their partners not staying together.

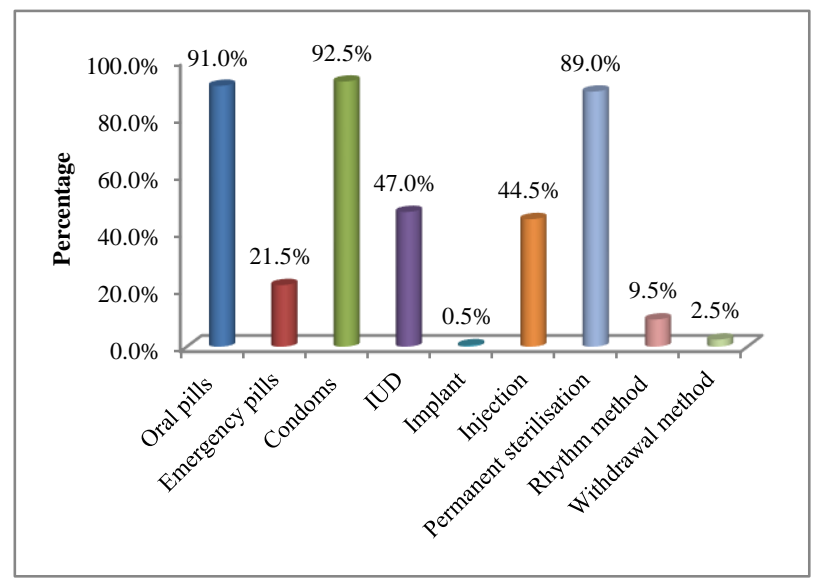

Figure 2: Knowledge of family planning method.

\section{The reasons for non-acceptance of family planning methods were}

Total $71.6 \%$ of the couples had fear of side effects of various family planning methods.62.7\% of the subjects gave the reason as plan to avoid sex which also included those whose partners are not staying together also.16.4\% were not using FP methods due to opposition from husbands.13.4\% didn't know about FP methods. 10.4\% avoided family planning methods due to religious restrictions. $1.5 \%$ planned to have another child immediately (Figure 3).

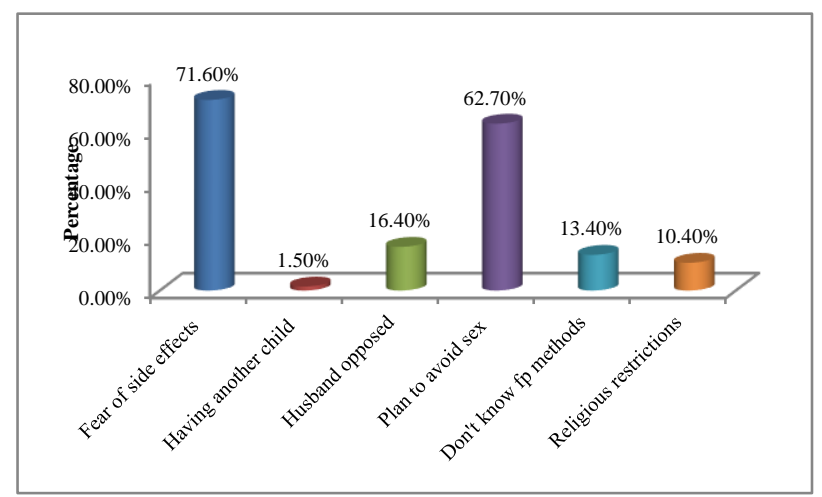

Figure 3: Percentage distribution of sample according to reasons for non-acceptance of birth spacing methods. 


\section{DISCUSSION}

The acceptance of birth spacing methods in our study came out as $56.8 \%$. Of these, $59.1 \%$ planned to use family planning methods 6 weeks after delivery while $40.9 \%$ planned to use it 6 months after delivery. This higher rate could be attributed to higher literacy rate and contraceptive awareness as well as the role of health education and proper counselling from the antenatal period itself. Even though the unmet need of birth spacing is $8.3 \%$ in India, the same stand was insignificant in our study setting due to free availability of all the birth spacing methods and cafeteria approach in delivering services. But ironically despite the contraceptive awareness and knowledge of its availability, the acceptance was only around $56 \%$. There were very few studies which focused on the acceptance of birth spacing methods alone.

Hence this study was important because it could throw light on the grey areas that needed to be addressed in order to increase the acceptance rate. Benny et al in their study from Thiruvananthapuram showed an acceptance rate of $71.1 \%(95 \%$ CI $63-78.5) .{ }^{12} 2$ other studies by Alina et al and Pawar et al got similar results. ${ }^{13,14}$ Suchithra et al in their study reported acceptance of birth spacing methods as $48.8 \%$, which was much less compared to present study.

\section{Demographic variables}

The acceptance of birth spacing methods in different age groups in our study population was $25 \%$ and was almost the same for every group. But Benny et al Pawar et al and Suchithra et al showed that the acceptance increases with increase in age of study population. ${ }^{12-14}$ In the present study the acceptance was found to be more in study subjects with higher education $(73.4 \%)(\mathrm{p}=0.003)$, higher educational level of husband $(\mathrm{p}=0.012)$, and higher socioeconomic status $(\mathrm{p}=0.015)$ religion of subject also showed a significant association with acceptance more among Hindus $(p=0.005)$. This can be attributed to religious restriction in other communities.

However, majority of the subjects in our study population were Hindus, so that could be confounding factor as well. These results was comparable to the study conducted by Alina et al Suchithra et al where religion, education, income, type of family, occupation, spouse education, spouse occupation were having a statistically significant association with contraceptive use. ${ }^{13,15}$ Bhavya et al in their Karnataka study found that the proportion of willingness for contraception was more among women in the 19-29 years group, $(\mathrm{p}<0.001)$ among literate husband and wife $(\mathrm{p}<0.01)$, among women belonging to nuclear families $(\mathrm{p}<0.001)$ and with higher socioeconomic status $(\mathrm{p}<0.001){ }^{16-20}$ The study done by Sanjith found that woman's age, education, religion, living children, sex preference, wealth index, significantly affect methods of choice among currently married women of India. ${ }^{17}$

\section{Obstetric factors and contraception acceptance}

Among the reproductive and fertility factors studied, there was no significant association with acceptance of birth spacing methods. In the present study it was found that younger age of wife at marriage showed higher acceptance of birth spacing services with $78 \%$ of females of the age group 18-20 years at time of marriage accepting family planning services, but statistical analysis didn't show significant association. Number of abortions, type of delivery, birth weight and sex of the child were not significantly associated with acceptance of birth spacing methods. Suchithra et al noted that number of children $(p<0.05)$ and number of male children $(p<0.0001)$, were statistically significant factors with current contraceptive use. ${ }^{15}$ Number of children were a determinant for the use of family planning method according to the several studies. ${ }^{12,14,16,18}$ Asari et al noted that gender preference did not determine contraceptive practices, but as per family welfare statistic report those who were having more number of male children will adopt family planning methods more than those having female child. ${ }^{19,21}$

\section{Decision making on family size}

In our study $98.5 \%$ of families took a consensual decision on contraception. In the study by Bhavya et al regarding limiting and spacing methods of family planning, the final decision was taken by family elders in $51.4 \%$ and by husband alone in $46.1 \% .^{20}$ Husband and wife both together took decision collectively in only $0.4 \%$ of families. This symbolizes a positive change towards women empowerment, female literacy and involvement of women in decision making may be reason for higher acceptance of contraception in our study population.

Awareness on contraceptive method was another important determinant for acceptance in our study which showed significant association $(p=0.01)$. The contraceptive awareness in our study population was around $95 \%$. The main source of information was health education through hospitals and health workers which was around $94 \%$ followed by mass media $61.5 \%$. Family $(26 \%)$ and friends $(8 \%)$ also were source of information in few subjects. Bhavya et al in their study showed that $48 \%$ of population had contraceptive awareness and the main reason for non-acceptance of family planning method was lack of awareness. ${ }^{20}$

\section{Knowledge of family planning method}

Regarding the various family planning methods known to the study population, $91 \%$ of subjects had knowledge about oral pills and condoms. This was followed by permanent sterilization that comes to $89 \%$. The awareness about DMPA injections and intrauterine devices were almost the same around 44.5 and $47 \%$ respectively. Emergency contraception was known to 21.5\%. The withdrawal and rhythm method were known 
to very few $(2.5 \%$ and $9.5 \%)$ which shows a transition from traditional to modern method of contraception. The usage of condom was preferred by those who had their partners staying together for limited period of time. This is of much significance in Kerala because of high proportion of migration of husbands to other countries.

Female sterilization was the most widely known contraceptive method, as per Benny et al which was about $97.8 \%$ but in study by Suchithra et al it was $71.9 \%$ and knowledge about CuT was $80.8 \% .^{14,15}$ IUD was getting more popularity there. The least known contraceptive method in that study was injectable contraceptives $(26.6 \%)$. In our study population $94 \%$ had awareness on availability of family planning services in public hospitals, $46 \%$ knew about its availability in pharmacies. A few were aware about its availability in private hospitals. This may be because our study setting was public hospital. Regarding the birth spacing method preferred by study population, the most common was injectable contraceptives $(47.1 \%)$ followed by intrauterine devices.(39.1\%) $13.8 \%$ preferred condom as method of contraception. The result showed that our study population gave more preference to long term contraception. Even though oral pills and condoms were the most known method of contraception those who were using it as a spacing method was limited. This could be due to fear of side effects, high failure rate and lack of convenience.

The main reason for non-acceptance of family planning method was fear of side effects $(71.6 \%)$. Even with very high level of contraceptive awareness, the fear of side effects was still very high. $62.7 \%$ has declined contraceptive use as they planned to avoid sex. This group also includes those whose partners are staying abroad. Other reasons for non-acceptance were opposition from husband $(16.4 \%)$, religious restriction $(10.4 \%)$ and lack of knowledge on family planning methods (13.4\%). Female literacy and education about the methods of spacing available as well as highlighting about the possible complications of termination of pregnancies even if rare would definitely increase acceptance. We need to emphasize regarding the need to prevent unplanned pregnancies over and over again.

\section{Limitations}

Limitations of current study were; this being a hospital based study has its own limitations. This study was a cross-sectional study done on convenient sampling of participants. It limits the external validity of the study. Further population-based studies on larger samples can shed light on the community perspectives on spacing methods

\section{CONCLUSION}

The acceptance of birth spacing methods in this tertiary care centre was $56.8 \%$ which was way higher than the
$7 \%$ as detailed by NFHS-4 data on acceptance of birth spacing methods. Among the various determinants studied, those which were significantly associated with acceptance of birth spacing methods were education of wife, husband's education, socioeconomic status, religion of subject and contraceptive awareness. The main source of contraceptive awareness was health education followed by mass media. The uses of contraception known to the population were child spacing, limiting the number of children and preventing unwanted pregnancy. The use of contraception as a measure to prevent maternal death and illness was not known to many. The most common birth spacing method preferred in our study was injectable contraception (DMPA) compared to studies in other settings where intrauterine device was the most preferred method. This was followed by intrauterine devices. The main reason for non-acceptance of family planning method was fear of side effects followed by plan to avoid sex for a specified time and to continue with next pregnancy should they conceive. Other factors noted were opposition from husband and religious restriction. Even though the study population was aware about use of birth spacing methods to improve maternal and child health, the knowledge on its prospect of decreasing the infant and maternal mortality was limited.

Funding: No funding sources

Conflict of interest: None declared

Ethical approval: The study was approved by the Institutional Ethics Committee

\section{REFERENCES}

1. Eliason S, Baiden F, Quansah-Asare G, GrahamHayfron Y, Bonsu D, Phillips J, Awusabo-Asare K. Factors influencing the intention of women in rural Ghana to adopt postpartum family planning. Reprod health. 2013;10(1):34.

2. Cates W, Karim QA, El-Sadr W, Haffner DW, Kalema-Zikusoka G, Rogo K, Petruney T, Averill EM. Family planning and the millennium development goals. Science. 2010;329(5999):1603-8.

3. Sachs JD, McArthur JW. The millennium project: a plan for meeting the millennium development goals. Lancet. 2005;365(9456):347-53.

4. Dhak B, Saggurti N, Ram F. Contraceptive use and its effect on Indian women"es empowerment: evidence from the National Family Health Survey-4. J Biosocial Sci. 2019;10:1.

5. Responsibility S. Women, society, and abortion worldwide. New York: Alan Guttmacher Insitute publication; 1999.

6. Maternal mortality in 2005. Available at: https://www.who.int/whosis/mme_2005.pdf. Accessed on 20 May 2021.

7. Lule E, Singh S, Chowdhury SA. Fertility regulation behaviors and their costs: Contraception and unintended pregnancies in Africa and Eastern Europe \& Central Asia. Available at: https://openknowledge. 
worldbank.org/handle/10986/13783. Accessed on 20 May 2021.

8. Conde-Agudelo A, Rosas-Bermúdez A, Kafury-Goeta AC. Birth spacing and risk of adverse perinatal outcomes: a meta-analysis. JAMA. 2006;295(15): 180923.

9. Singh S, Darroch JE, Ashford LS, Vlassoff M. Adding it up: the costs and benefits of investing in family planning and maternal and new born health. Available at: https://www.guttmacher.org/ report/adding-it-costs-and-benefits-investing-familyplanning-and-maternal-and-newborn-health. Accessed on 20 May 2021.

10. India ${ }^{\text {ee }}$ vision FP 2020. Available at: https://advancefamilyplanning.org/sites/default/files/r esources/FP2020-Vision-Document\%20India.pdf. Accessed on 20 May 2021.

11. Jain AK, Winfrey W. Contribution of contraceptive discontinuation to unintended births in 36 developing countries. Family Planning J. 2017;48(3):26978.

12. Benny PV, Regi J, Anil BS. Pattern of contraceptive use among married women of reproductive age group in a rural panchayat in Kerala. Int J Med App Sci. 2013;2(3):287-92.

13. Alina AM, Saju CR, Catherin N. Family planning practices among married women of reproductive age group in a rural area in Thrissur District, Kerala, India. Int J Curr Res Acad Rev. 2015;3(11):36-42

14. Pawar AT, John A, Kumar D. Family planning practices in rural Kerala. Scholars J App Med Sci. 2014;2:19-21.

15. Suchithra ET, Sujina CM. Current Practice and Determinants of Family Planning Methods among
Married Females in the Reproductive Age Group (15$49 y r s$ ) in a rural Setting, Kerala. Indian $\mathbf{J}$ Foren Community Med. 2016;3(1):13-9.

16. Padmaja Ravindra Walveker: Determinants of contraceptive use among married woman residing in rural areas of Belgaum. J Med Allied Sci. 2012; 2(1):7-11.

17. Sarkar S. Socio-demographic Differentials and Determinants of Contraception Methods Choice among currently married women in India. Available at: https://iussp.org/sites/default/files/event_call_for_ papers/IUSSP_long\%20abstruct_contraception_sanjit $\% 20$ sarkar.pdf. Accessed on 20 May 2021.

18. Rajaretnam T. Sociocultural determinants of contraceptive method choice in Goa and Kerala India. J Family Welfare. 2000;46(2):1.

19. Asari VG, Thulaseedharan JV. Contraceptive use and preferences of young married women in Kerala, India. Open Access J Contracept. 2018;9:1-10.

20. Rao BS, Mathada VC. Awareness and determinants of contraceptive use among nursing mothers in Bellary, Karnataka. J Clin Diagn Res. 2016;10(1):QC15.

21. Family Welfare Statistics in India 2011. Available at: https://main.mohfw.gov.in/sites/default/files/Healthan dFamilyWelfarestatisticsinIndia201920.pdf. Accessed on 20 May 2021.

Cite this article as: Nair RP, Nambisan B, Brahmanandan M. Acceptance of birth spacing methods and it's determinants among postnatal women in a tertiary care setting from Kerala. Int J Reprod Contracept Obstet Gynecol 2021;10:3921-8. 